Lynda M. Vrooman, Kristen E. Stevenson, Jane O'Brien, Suzanne Dahlberg, Donna S Neuberg, Stephen E. Sallan, and Lewis B. Silverman, Dana-Farber Cancer Institute; Lynda M. Vrooman, Stephen E. Sallan, and Lewis B. Silverman, Boston Children's Hospital; Jeffrey G. Supko, Massachusetts General Hospital, Boston; Jeffery L. Kutok, Infinity Pharmaceuticals, Cambridge, MA; Barbara L. Asselin, University of Rochester Medical Center, Rochester; Kara M. Kelly, Columbia University Medical Center, Morgan Stanley Children's Hospital of New York-Presbyterian, New York, NY; Luis Clavell, San Jorge Children's Hospital, San Juan, Puerto Rico; Steven E. Lipshultz, University of Miami Leonard M. Miller School of Medicine, Miami, FL; Marshall Schorin, Inova Fairfax Hospital for Children, Falls Church, VA; Mary V. Relling, St Jude Children's Research Hospital, Memphis, TN; Harvey J. Cohen, Stanford University School of Medicine, Stanford, CA; Uma H. Athale, McMaster University, Hamilton, Ontario; Caroline Laverdière, Hospital Sainte Justine, University of Montreal Montreal; and Bruno Michon, Centre Hospitalier Universitaire de Quebec Quebec City, Quebec, Canada.

Published online ahead of print at www.jco.org on January 28, 2013.

Authors' disclosures of potential conflicts of interest and author contributions are found at the end of this article.

Clinical trial information: NCT00165178.

Corresponding author: Lynda M. Vrooman, MD, Dana-Farber Cancer Institute, 450 Brookline Ave, Boston, MA, 02215; e-mail: lynda_vrooman@dfci.harvard.edu.

C 2013 by American Society of Clinical Oncology

0732-183X/13/3109-1202/\$20.00

DOI: $10.1200 / \mathrm{JCO} .2012 .43 .2070$

\title{
Postinduction Dexamethasone and Individualized Dosing of Escherichia Coli L-Asparaginase Each Improve Outcome of Children and Adolescents With Newly Diagnosed Acute Lymphoblastic Leukemia: Results From a Randomized Study-Dana-Farber Cancer Institute ALL Consortium Protocol 00-01
}

Lynda M. Vrooman, Kristen E. Stevenson, Jeffrey G. Supko, Jane O’Brien, Suzanne E. Dahlberg, Barbara L. Asselin, Uma H. Athale, Luis A. Clavell, Kara M. Kelly, Jeffery L. Kutok, Caroline Laverdière, Steven E. Lipshultz, Bruno Michon, Marshall Schorin, Mary V. Relling, Harvey J. Cohen, Donna S. Neuberg, Stephen E. Sallan, and Lewis B. Silverman

\section{$\begin{array}{lllllllll}\text { A } & \text { B } & \text { S } & \text { T } & \text { R } & \text { A } & \text { C } & \text { T }\end{array}$}

\section{Purpose}

We assessed the toxicity and efficacy of dexamethasone and a novel dosing method of Escherichia coli L-asparaginase (EC-Asnase) in children and adolescents with newly diagnosed acute lymphoblastic leukemia (ALL).

\section{Patients and Methods}

Patients achieving complete remission (CR) on Dana-Farber Cancer Institute ALL Consortium Protocol 00-01 were eligible for random assignment to 1) dexamethasone or prednisone, administered as 5-day pulses, every 3 weeks, and 2) weekly EC-Asnase, administered as a 25,000 $\mathrm{IU} / \mathrm{m}^{2}$ fixed dose (FD) or individualized dose (ID) starting at 12,500-IU/ $\mathrm{m}^{2}$, adjusted every 3 weeks based on nadir serum asparaginase activity (NSAA) determinations.

\section{Results}

Between 2000 and 2004, 492 evaluable patients (ages 1 to 18 years) enrolled; 473 patients (96\%) achieved CR. Four hundred eight patients (86\%) participated in the corticosteroid randomization and 384 patients $(81 \%)$ in the EC-Asnase randomization. With 4.9 years of median follow-up, dexamethasone was associated with superior 5-year event-free survival (EFS; $90 \% \vee 81 \%$ for prednisone; $P=.01)$ but higher rates of infection $(P=.03)$ and, in older children, higher cumulative incidence of osteonecrosis $(P=.02)$ and fracture $(P=.06)$. ID EC-Asnase had superior 5-year EFS (90\% $\vee 82 \%$ for FD; $P=.04)$, but did not reduce the frequency of asparaginase-related toxicity. Multivariable analysis identified both dexamethasone and ID EC-Asnase as independent predictors of favorable EFS.

\section{Conclusion}

There was no overall difference in skeletal toxicity by corticosteroid type; dexamethasone was associated with more infections and, in older children, increased incidence of osteonecrosis and fracture. There was no difference in asparaginase-related toxicity by EC-Asnase dosing method. Dexamethasone and ID EC-Asnase were each associated with superior EFS. Monitoring NSAA during treatment with EC-Asnase may be an effective strategy to improve outcome in pediatric ALL.

\section{J Clin Oncol 31:1202-1210. C 2013 by American Society of Clinical Oncology}

\section{INTRODUCTION}

Corticosteroids and L-asparaginase are universal components of chemotherapy regimens for childhood acute lymphoblastic leukemia (ALL), although both are associated with significant adverse effects. Interest in substituting dexamethasone for prednisone in ALL treatment arose from studies suggesting that dexamethasone had more potent in vitro antileukemia activity, higher free-plasma levels, and enhanced CSF penetration. ${ }^{1,2}$ Results of some randomized trials have indicated that dexamethasone was associated with superior event-free survival (EFS), whereas others have found no 
difference in outcome. ${ }^{3-6}$ Dexamethasone has been associated with increased toxicities, including higher rates of osteonecrosis, especially in older children and adolescents. ${ }^{7}$ Thus, the optimal corticosteroid preparation and dosing are unknown, and may differ for patient subgroups.

Similarly, optimal dosing for asparaginase remains unclear. Asparaginase-associated toxicities, such as allergy, pancreatitis, and thrombosis, are a significant source of morbidity and may increase relapse risk in patients unable to receive all intended doses. ${ }^{8}$ It has been suggested that serum asparaginase activity levels $\geq 0.10 \mathrm{IU} / \mathrm{mL}$ are required for therapeutic asparagine depletion. ${ }^{9-14}$ However, interpatient variability in asparaginase activity levels is high among children receiving a fixed dose (FD; based on body surface) of Escherichia coli L-asparaginase (EC-Asnase). ${ }^{9,12,15}$ We hypothesized that an individual dosing regimen, monitoring nadir serum asparaginase activity (NSAA) and adjusting the EC-Asnase dose to maintain a therapeutic level, would improve tolerability and outcome.

Dana-Farber Cancer Institute ALL Consortium Protocol 00-01 focused on optimizing the use of corticosteroids and EC-Asnase in children and adolescents with newly diagnosed ALL. The primary objectives of this study were to determine the relative toxicity, tolerability, and efficacy of 1) dexamethasone and prednisone administered during postinduction treatment and 2) weekly intramuscular ECAsnase administered as the standard FD and a pharmacokinetically guided individualized dose (ID). In this article, we report the findings of Protocol 00-01.

\section{PATIENTS AND METHODS}

\section{Patients}

Patients ages 1 to 18 years with newly diagnosed ALL (excluding mature B-cell ALL) were eligible for enrollment. The protocol was approved by the institutional review boards of each participating institution (Appendix Table A1, online only). ${ }^{16}$ Informed consent was obtained from parents or guardians for each patient before enrollment.

\section{Risk Groups}

Patients were stratified into risk groups for treatment. Standard risk was defined as: patients ages 1 to 9.99 years, presenting WBC count less than $50,000 / \mu \mathrm{L}, \mathrm{B}$-precursor phenotype, no mediastinal mass, and diagnostic spinal fluid without blasts (CNS1) or with blasts but fewer than five leukocytes per high-power field. All other patients were defined as high risk. Patients with Philadelphia chromosome $(\mathrm{Ph}+)$ were considered to be high risk but were eligible for allogeneic hematopoietic stem-cell transplantation in first complete remission (CR). Patients with $M L L$ gene rearrangement received an additional postinduction intensification cycle and then continued as high risk. ${ }^{17}$

\section{Therapy}

Details of treatment are summarized in Table 1. All patients received prednisone during induction. Patients with persistent morphologic leukemia after 1 month were removed from study and received alternative therapy. ${ }^{18}$ Corticosteroids were permanently discontinued in the setting of symptomatic, radiographically confirmed osteonecrosis and were temporarily held for bone fracture (resumed when the fracture healed). EC-Asnase was held until resolution of mild/moderate pancreatitis or thrombosis and was permanently discontinued after severe pancreatitis. Patients with allergic reactions to ECAsnase of any severity, including local reactions, were switched to Erwinia asparaginase $\left(25,000 \mathrm{IU} / \mathrm{m}^{2}\right)$ two times per week. ${ }^{16}$ Patients were switched to weekly intramuscular polyethylene glycol-asparaginase on allergy to or unavailability of Erwinia asparaginase. Asparaginase was permanently discontin- ued after allergy to all available preparations. Therapy for all patients was discontinued after 24 months of continuous CR.

\section{Randomizations}

Patients who achieved CR were eligible for two randomized comparisons. Patients who declined participation in random assignments and $\mathrm{Ph}+$ patients were directly assigned to receive prednisone and FD EC-Asnase.

\section{Corticosteroid Randomization}

Standard-risk patients were randomly assigned to receive either dexamethasone $6-\mathrm{mg} / \mathrm{m}^{2} /$ day or prednisone $40 \mathrm{mg} / \mathrm{m}^{2} /$ day, administered as 5 -day pulses every 3 weeks beginning at week 7 , until the completion of therapy. High-risk patients received either dexamethasone $18-\mathrm{mg} / \mathrm{m}^{2} /$ day or prednisone $120 \mathrm{mg} / \mathrm{m}^{2} /$ day during the 30 -week intensification phase, and then the same corticosteroid dose as standard-risk patients during the continuation phase. ${ }^{8,19}$

\section{Asparaginase Randomization}

During intensification, patients were scheduled to receive 30 weekly doses of IM EC-Asnase. Patients were randomly assigned to receive either FD $\left(25,000 \mathrm{IU} / \mathrm{m}^{2}\right)$ or ID, based on monitoring NSAA. The initial dose for the ID arm was $12,500 \mathrm{IU} / \mathrm{m}^{2}$, with subsequent doses adjusted to maintain NSAA between 0.10 and $0.14 \mathrm{IU} / \mathrm{mL}$ using the algorithm in Table 1 .

Samples for monitoring NSAA were obtained from all patients just before administering the second and fourth EC-Asnase doses and every 3 weeks thereafter. Procedures for sample collection, processing, storage, and determining NSAA have been previously described. ${ }^{16}$ Only samples obtained 7 days after the prior dose were considered evaluable for dose adjustment and statistical analysis. EC-Asnase antibodies were assayed as previously described in samples obtained every 6 weeks from all patients and when NSAA was below the level of detectability $(<0.025 \mathrm{IU} / \mathrm{mL})$ in ID patients. ${ }^{20,21}$ ID patients with NSAA less than $0.1 \mathrm{IU} / \mathrm{mL}$ on successive determinations despite dose adjustment or when coupled with EC-Asnase antibody positivity were considered to have "silent inactivation" and were switched to Erwinia- or polyethylene glycol-asparaginase. Clinical allergic reaction was the only planned indication for switching asparaginase preparation for FD patients.

\section{Toxicity Assessment}

Toxicity data were prospectively collected. For the corticosteroid randomization, the primary toxicity end points were symptomatic osteonecrosis and fracture, confirmed by radiographic imaging. A diagnosis of bacteremia or fungemia was based on positive blood culture; invasive fungal disease was diagnosed by radiographic imaging, plus/minus culture results. Asparaginaseassociated toxicities included allergy, thrombosis (radiographically confirmed), and pancreatitis. Pancreatitis cases were classified by duration of clinical signs/symptoms as mild/moderate ( $<72$ hours in duration) or severe ( $\geq 72$ hours).

\section{Minimal Residual Disease}

End-induction marrow aspirates were collected prospectively for patients with B-precursor immunophenotype and were analyzed for minimal residual disease by a polymerase chain reaction-based methodology. ${ }^{22}$ Results were not used to adjust treatment.

\section{Statistical Methods}

Descriptive statistics are presented as frequencies and percentages. The 5 -year cumulative incidence (CumInc) of osteonecrosis and fracture were estimated using the CumInc utility in the cmprsk package in R and tested using the Gray test, with relapse and death in remission identified as competing risks. Frequencies of infection and asparaginase toxicities were identified and analyzed with the Fisher's exact test. The study was designed to test for differences in the rate of asparaginase-related toxicity between FD and ID and of bony morbidity (osteonecrosis and fracture) between dexamethasone and prednisone. Four hundred three patients were calculated to provide $90 \%$ power to detect a difference between $36 \%$ and $21 \%$ in asparaginase-related toxicity using a two-sided .05 level test and $80 \%$ power to detect a difference between $16 \%$ and $28 \%$ incidence of bony morbidity using a two-sided .05 level test. 
Table 1. Therapy on DFCl-ALL Consortium Protocol 00-01

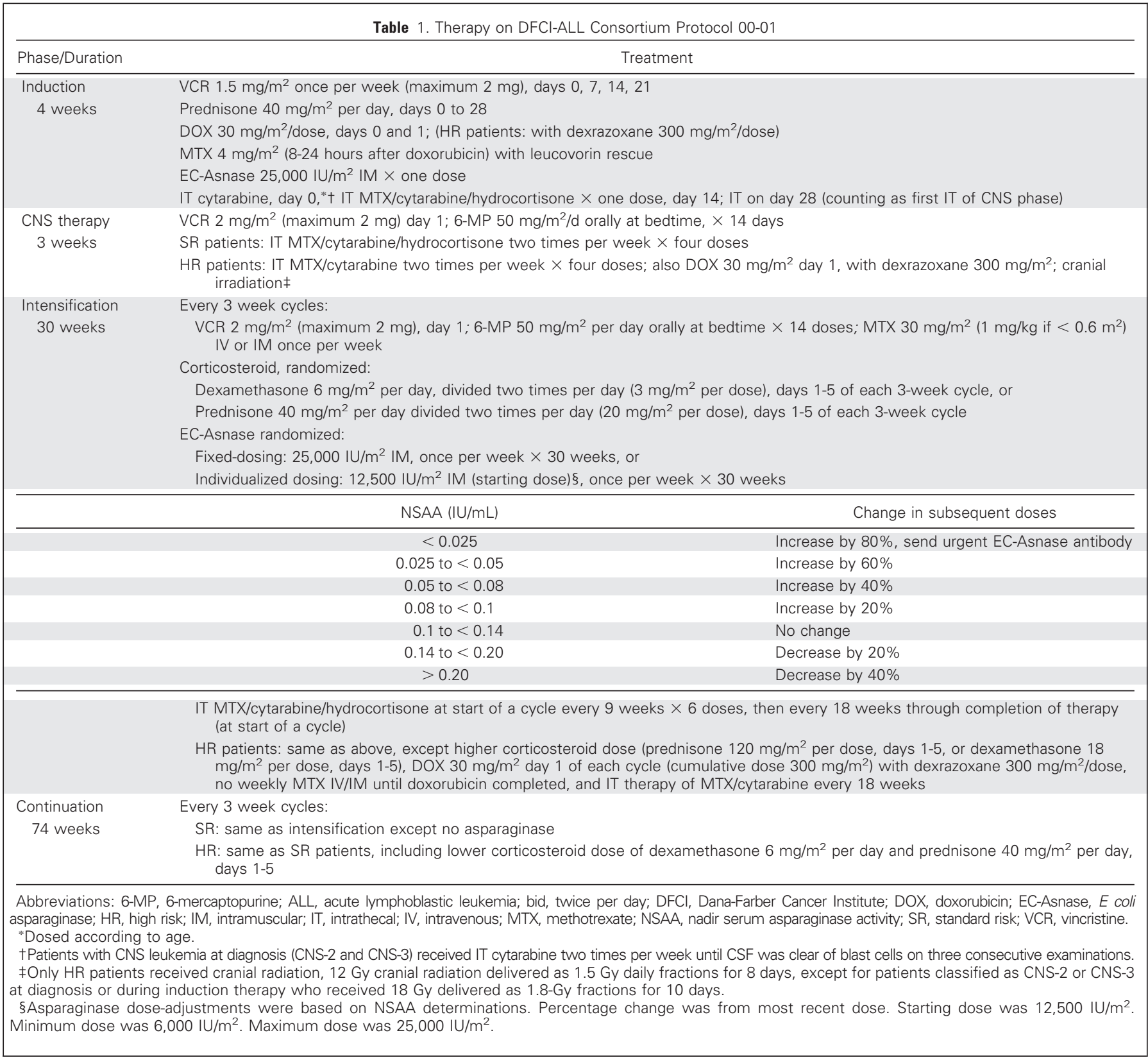

For overall protocol results, EFS was defined as the time from diagnosis to first outcome event (induction failure, induction death, death during remission, or relapse). Overall survival (OS) was calculated from the time of diagnosis to death from any cause. EFS and OS were estimated using Kaplan-Meier methodology, and the Greenwood formula was used to construct 95\% CI, which were truncated at $100 \%$. The log-rank test was used to compare EFS and OS between groups. Multivariable regression analysis was conducted using Cox proportional hazards models (Appendix, online only).

Analyses of both randomizations were by intention-to-treat for all patients achieving CR. Because the analysis of patients participating in the randomizations included only those alive and in $\mathrm{CR}$ at the start of the intensification phase, a landmark approach defined at this time-point was used for EFS estimates. EFS and OS were planned secondary end points of the randomized comparisons.

No adjustments were made for performing multiple statistical tests. $P$ values are two-sided and values less than .05 were considered significant.

\section{RESULTS}

\section{Patient Characteristics}

Between September 2000 and December 2004, 498 patients (ages 1 to 18 years) were enrolled, 492 of whom were considered evaluable (five were subsequently found ineligible and one withdrew consent; Fig 1; Table 2). Median follow-up was 4.9 years.

\section{Overall Results}

Four hundred seventy-three patients (96\%) achieved CR, 13 patients $(3 \%)$ had persistent leukemia at the end of the first month, and three patients $(0.6 \%)$ died during induction (two patients from infection/sepsis and one from necrotizing colitis). Three patients 


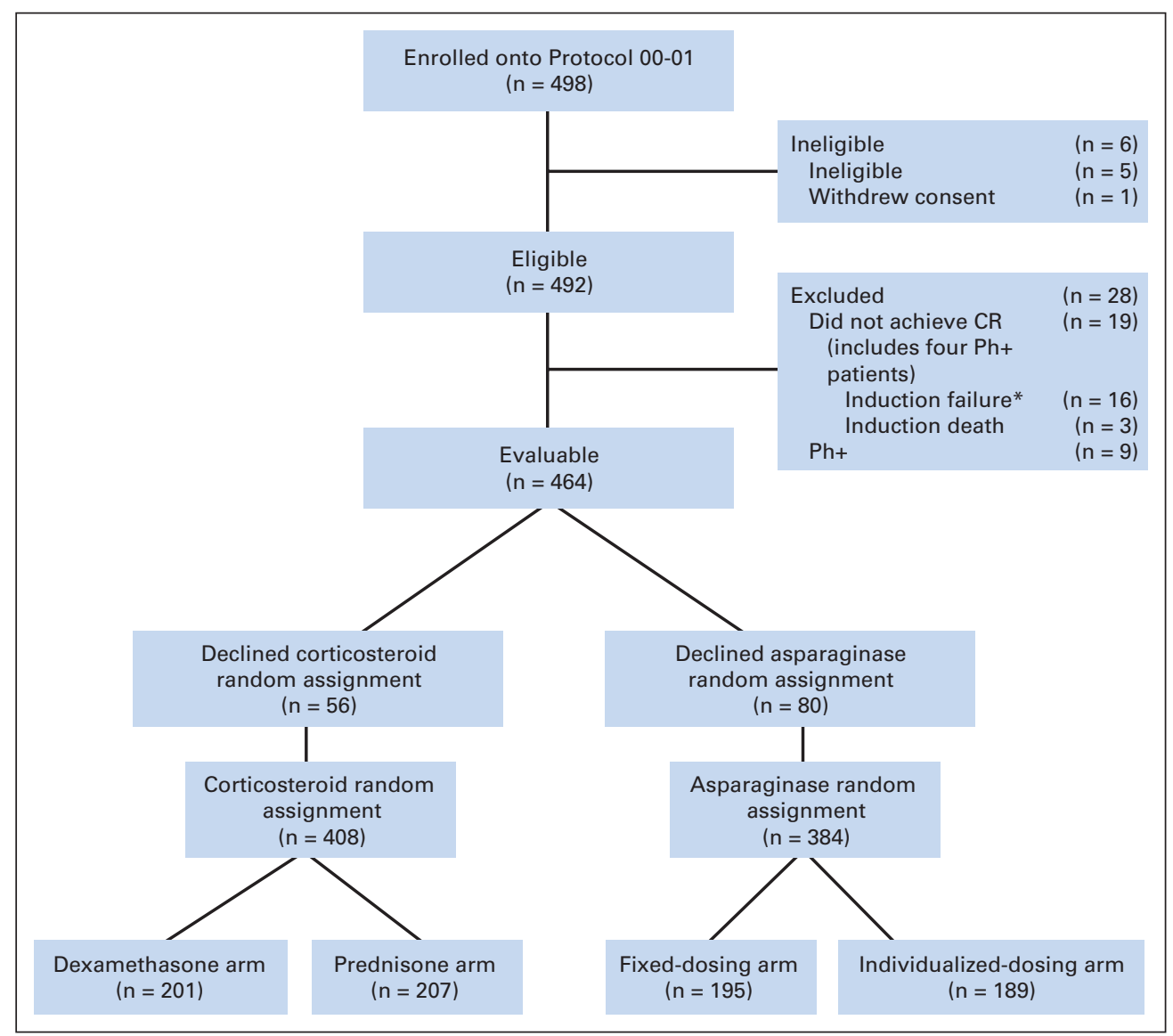

Fig 1. Dana-Farber Cancer Institute Acute Lymphoblastic Leukemia (ALL) Consortium Protocol 00-01 flow diagram. Patients with newly diagnosed ALL were enrolled ( $N=498$ ); 492 patients were considered evaluable. Of these 492 patients, 473 patients achieved complete remission (CR). Of the 473 patients who achieved CR, 408 patients (86\%) participated in the corticosteroid random assignment and $384(81 \%)$ in the asparaginase random assignment. $\mathrm{Ph}$, Philadelphia chromosome. ${ }^{*}$ ) Includes 13 patients with persistent leukemia at end of first month and three patients who did not recover blood counts by day 49
$(0.6 \%)$ failed to recover blood counts by day 49 of treatment and were removed from protocol. Of those who achieved CR, 69 patients (15\%) relapsed and five patients (1\%) died while in first CR as a result of infection/sepsis $(\mathrm{n}=3)$ and complications of hematopoietic stem-cell transplantation (two $\mathrm{Ph}+$ patients). No second malignant neoplasms have been reported. The estimated 5-year EFS and OS for all 492 patients were $80 \%$ (95\% CI, $76 \%$ to $84 \%)$ and $91 \%$ (95\% CI, $88 \%$ to 93\%), respectively (Fig 2A).

Of the 473 patients who achieved CR, 408 patients ( $86 \%$ ) participated in the corticosteroid randomization (prednisone, 207; dexamethasone, 201) and 384 patients (81\%) participated in the asparaginase randomization (FD, 195; ID, 189). Presenting characteristics did not differ significantly between treatment arms.

\section{Corticosteroid Randomization}

Osteonecrosis. Of the 408 randomly assigned patients, 23 patients $(6 \%)$ had symptomatic osteonecrosis (six patients at more than one site). Osteonecrosis was more frequently diagnosed in patients 10 to 18 years old than in younger patients (5-year CumInc, $14 \%$ v 3.5\%; $P=.0004)$. Five-year osteonecrosis CumInc did not differ by sex $(P=.15)$.

The overall incidence of osteonecrosis did not differ by corticosteroid type ( $P=.25$; Appendix Table A2, online only). However, for patients 10 to 18 years, dexamethasone was associated with a higher risk of osteonecrosis (5-year CumInc, 23\% v 5\% for patients randomly assigned to prednisone; $P=.02$ ). Osteonecrosis CumInc did not differ by corticosteroid type in children 1 to 9.99 years old $(P=.43)$. For high-risk patients ages 1 to 9.99 years randomly assigned to dexamethasone, osteonecrosis CumInc was 3\%, similar to that of standard-risk patients and significantly less than older high-risk patients (5-year CumInc, $23 \% ; P<.01)$. For high-risk patients randomly assigned to prednisone, there was no significant difference in osteonecrosis CumInc in those patients 1 to 9.99 years old $(0 \%)$ versus patients 10 to 18 years old $(5 \% ; P=.92)$.

Fracture. Fifty-six patients (14\%) were diagnosed with a bone fracture (10 patients with more than one fracture). Five-year CumInc in patients ages 10 to 18 years was $19 \%$ compared with $12 \%$ for younger patients $(P=.06)$. There was no difference in fracture CumInc by corticosteroid randomization $(P=.89)$. For patients 10 to 18 years old, fracture CumInc for those patients randomly assigned to dexamethasone was $29 \%$ compared with $10 \%$ for those randomly assigned to prednisone $(P=.06)$.

Infection. Postinduction infections were documented in $60 \mathrm{pa}-$ tients (15\%), including 12 (13\%) of 91 patients ages 10 to 18 years and $48(15 \%)$ of 317 patients ages 1 to 9.99 years $(P=.74)$. The infection rate differed by corticosteroid type; 22 patients (11\%) randomly assigned to prednisone had $\geq$ one infection compared with 38 patients (19\%) randomly assigned to dexamethasone $(P=.03$; Appendix Table A2). The infection rate was higher for patients 10 to 18 years old in the dexamethasone arm compared with the prednisone arm $(P=.004)$, but for patients 1 to 9.99 years old, infection rate did not significantly differ by corticosteroid type $(P=.27)$. There was one infection-related death in a child randomly assigned to prednisone 
Table 2. Patient Characteristics and 5-Year EFS Survival Rates of Children and Adolescents With Newly Diagnosed ALL Treated on DFCl ALL Consortium Protocol 00-01 ( $\mathrm{N}=492)$

\begin{tabular}{|c|c|c|c|c|}
\hline Characteristic & $\begin{array}{l}\text { Total No. } \\
\text { of Patients }\end{array}$ & $\begin{array}{l}\text { 5-Year } \\
\text { EFS (\%) }\end{array}$ & $95 \% \mathrm{Cl}$ & $P$ \\
\hline All evaluable patients & 492 & 80 & 76 to 84 & \\
\hline DFCl risk group & & & & .001 \\
\hline Standard risk & 282 & 85 & 80 to 89 & \\
\hline High risk & 210 & 74 & 68 to 80 & \\
\hline Age, years & & & & .008 \\
\hline $1-9.99$ & 380 & 83 & 79 to 87 & \\
\hline $10-18$ & 112 & 72 & 63 to 80 & \\
\hline Median & \multicolumn{2}{|c|}{4.75} & & \\
\hline Range & \multicolumn{2}{|c|}{$1-17.8$} & & \\
\hline WBC count, $\times 10^{9} / \mathrm{L}$ & & & & .007 \\
\hline$<50,000$ & 391 & 83 & 78 to 87 & \\
\hline$\geq 50,000$ & 101 & 72 & 63 to 81 & \\
\hline Median & \multicolumn{2}{|c|}{11.4} & & \\
\hline Range & \multicolumn{2}{|c|}{$0.9-865.1$} & & \\
\hline Sex & & & & .04 \\
\hline Male & 264 & 77 & 71 to 82 & \\
\hline Female & 228 & 85 & 80 to 90 & \\
\hline Immunophenotype & & & & .01 \\
\hline B lineage & 443 & 82 & 78 to 85 & \\
\hline T cell & 49 & 69 & 56 to 82 & \\
\hline CNS status at diagnosis & & & & .68 \\
\hline CNS 1 & 410 & 80 & 76 to 84 & \\
\hline CNS 2 & 60 & 84 & 74 to 93 & \\
\hline CNS 3 & 17 & 81 & 62 to 100 & \\
\hline Missing & 5 & & & \\
\hline Down syndrome & & & & .34 \\
\hline Yes & 13 & 92 & 76 to 100 & \\
\hline No & 479 & 80 & 76 to 84 & \\
\hline End-induction MRD* & 186 & & & $<.0001$ \\
\hline Low & 168 & 87 & 81 to 92 & \\
\hline High & 18 & 61 & 35 to 79 & \\
\hline Cytogeneticst & 405 & & & \\
\hline TEL/AML 1 & 98 & 91 & 85 to 97 & \\
\hline High hyperdiploid & 110 & 88 & 81 to 95 & \\
\hline $\mathrm{t}(1 ; 19)$ & 14 & 100 & & \\
\hline $\mathrm{t}(9 ; 22)$ & 14 & 31 & 6 to 56 & \\
\hline$M L L$ rearrangement & 14 & 48 & 21 to 75 & \\
\hline
\end{tabular}

NOTE. Bone marrow cells from diagnostic aspirate samples were examined for cell-surface antigens using direct immunofluorescence assays and were cultured for cytogenetic analyses. Screening for the following translocations by FISH and/or PCR was performed at each participating institution when diagnostic marrow sample was available: TEL/AML1, MLL gene rearrangements, and BCR-ABL.

Abbreviations: ALL, acute lymphoblastic leukemia; DFCl, Dana-Farber Cancer Institute; EFS, event-free survival; FISH, fluorescent in situ hybridization:

$M R D$, minimal residual disease; PCR, polymerase chain reaction.

*Includes only B-precursor patients with evaluable MRD results $(n=186)$.

†Includes only patients with evaluable cytogenetic, FISH, and/or PCR results ( $n=405)$.

(from invasive fungal disease) and no infection-related deaths among patients on the dexamethasone arm.

EFS and OS. The estimates of EFS and OS included only patients who were alive and in CR at the start of intensification. The 5-year EFS was $81 \%$ (95\% CI, 75\% to $87 \%$ ) for patients on the prednisone arm and $90 \%$ (95\% CI, 85\% to $94 \%)$ for dexamethasone-arm patients $(P=.01$; Fig 2B). The trend toward superior EFS with dexamethasone was observed in subsets defined by age, risk group, phenotype, and other characteristics (Table 3). Sites of relapse are listed in Appendix

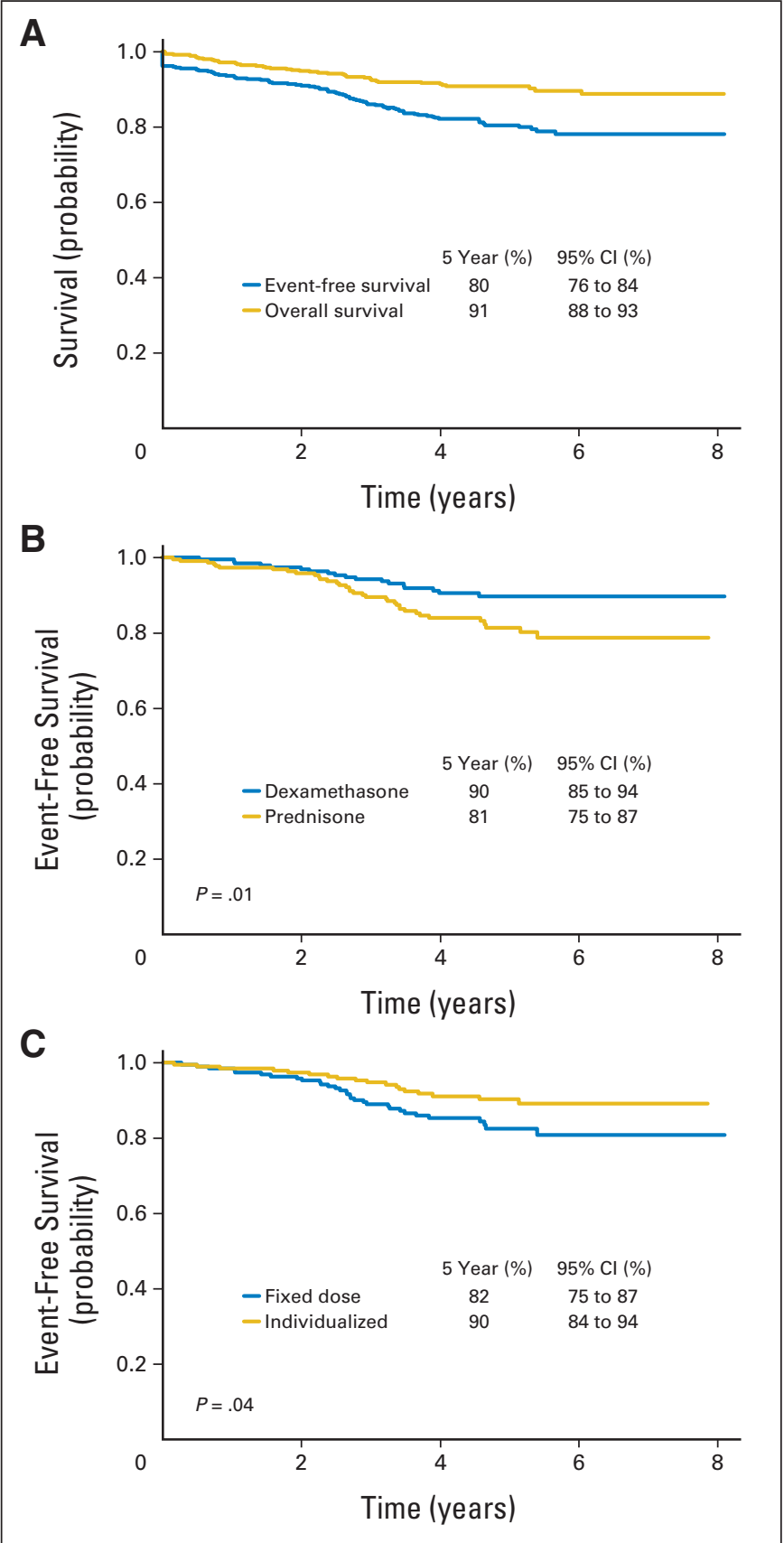

Fig 2. (A) Event-free survival (EFS) and overall survival (OS) for all patients. With a median follow-up of 4.9 years, the 5 -year EFS for 492 evaluable patients was $80 \%(95 \% \mathrm{Cl}, 76 \%$ to $84 \%)$ and the 5 -year OS was $91 \%(95 \% \mathrm{Cl}, 88 \%$ to $93 \%)$. (B) EFS results of corticosteroid randomization. The 5-year EFS for patients randomly assigned to prednisone was $81 \%(95 \% \mathrm{Cl}, 75 \%$ to $87 \%)$ compared with $90 \%(95 \% \mathrm{Cl}, 85 \%$ to $94 \%)$ for those randomly assigned to dexamethasone $(P=.01)$. (C) EFS results of asparaginase randomization. The 5-year EFS for patients randomly assigned to fixed-dosing of asparaginase was $82 \%(95 \% \mathrm{Cl}$, $75 \%$ to $87 \%$ ) compared with $90 \%(95 \% \mathrm{Cl}, 84 \%$ to $94 \%)$ for those randomly assigned to individualized dosing $(P=.04)$.

Table A3 (online only). There was no significant difference in 5-year OS (prednisone arm, 94\%; dexamethasone arm, 95\%; $P=.31$ ).

\section{Asparaginase Randomization}

NSAA and asparaginase antibodies. Data pertaining to NSAA and asparaginase antibody determinations are summarized in Table 4. A 


\begin{tabular}{|c|c|c|c|c|c|c|c|c|c|c|c|c|}
\hline \multirow[b]{3}{*}{ Patient Group } & \multicolumn{6}{|c|}{ Corticosteroid Random Assignment } & \multicolumn{6}{|c|}{ Asparaginase Random Assignment } \\
\hline & \multicolumn{3}{|c|}{ Dexamethasone } & \multicolumn{3}{|c|}{ Prednisone } & \multicolumn{3}{|c|}{ Fixed Dose } & \multicolumn{3}{|c|}{ Individualized Dose } \\
\hline & $\begin{array}{c}\text { No. of } \\
\text { Patients }\end{array}$ & $\begin{array}{l}\text { 5-Year } \\
\text { EFS (\%) }\end{array}$ & $95 \% \mathrm{Cl}$ & $\begin{array}{c}\text { No. of } \\
\text { Patients }\end{array}$ & $\begin{array}{c}\text { 5-Year } \\
\text { EFS (\%) }\end{array}$ & $95 \% \mathrm{Cl}$ & $\begin{array}{l}\text { No. of } \\
\text { Patients }\end{array}$ & $\begin{array}{c}\text { 5-Year } \\
\text { EFS (\%) }\end{array}$ & $95 \% \mathrm{Cl}$ & $\begin{array}{c}\text { No. of } \\
\text { Patients }\end{array}$ & $\begin{array}{c}\text { 5-Year } \\
\text { EFS (\%) }\end{array}$ & $95 \% \mathrm{Cl}$ \\
\hline All evaluable patients & 201 & 90 & 85 to 94 & 207 & 81 & 75 to 87 & 195 & 82 & 75 to 87 & 189 & 90 & 84 to 94 \\
\hline \multicolumn{13}{|l|}{ Risk group } \\
\hline SR & 114 & 89 & 83 to 95 & 121 & 84 & 76 to 91 & 110 & 86 & 76 to 92 & 115 & 89 & 81 to 93 \\
\hline $\mathrm{HR}$ & 87 & 91 & 84 to 97 & 86 & 78 & 69 to 87 & 85 & 78 & 66 to 86 & 74 & 93 & 84 to 97 \\
\hline \multicolumn{13}{|l|}{ Age, years } \\
\hline $1-9.99$ & 153 & 91 & 86 to 95 & 164 & 82 & 76 to 89 & 151 & 85 & 77 to 90 & 147 & 90 & 83 to 94 \\
\hline $10-18$ & 48 & 88 & 77 to 98 & 43 & 77 & 64 to 89 & 44 & 72 & 55 to 84 & 42 & 90 & 76 to 96 \\
\hline \multicolumn{13}{|l|}{ WBC count, $\times 10^{9} / \mathrm{L}$} \\
\hline$<50,000$ & 159 & 91 & 86 to 96 & 163 & 84 & 77 to 90 & 152 & 84 & 76 to 89 & 155 & 89 & 83 to 94 \\
\hline$\geq 50,000$ & 42 & 87 & 76 to 98 & 44 & 73 & 59 to 87 & 43 & 77 & 61 to 87 & 34 & 93 & 75 to 98 \\
\hline \multicolumn{13}{|l|}{ Sex } \\
\hline Male & 100 & 87 & 79 to 94 & 89 & 78 & 69 to 86 & 112 & 77 & 67 to 84 & 90 & 87 & 77 to 92 \\
\hline Female & 101 & 93 & 88 to 99 & 118 & 86 & 79 to 94 & 83 & 90 & 81 to 95 & 99 & 93 & 86 to 97 \\
\hline \multicolumn{13}{|l|}{ Immunophenotype } \\
\hline T cell & 22 & 96 & 87 to 100 & 17 & 65 & 42 to 87 & 20 & 74 & 49 to 88 & 15 & 100 & \\
\hline B lineage & 179 & 89 & 84 to 94 & 190 & 83 & 77 to 94 & 175 & 83 & 76 to 89 & 174 & 89 & 83 to 93 \\
\hline \multicolumn{13}{|l|}{ Cytogenetics } \\
\hline TEL/AML 1 & 43 & 100 & & 40 & 85 & 73 to 97 & 41 & 88 & 77 to 99 & 45 & 95 & 89 to 100 \\
\hline High hyperdiploid* & 44 & 95 & 87 to 100 & 52 & 83 & 71 to 95 & 47 & 88 & 77 to 98 & 38 & 89 & 76 to 100 \\
\hline
\end{tabular}

total of 2,536 evaluable NSAA samples were obtained from $95 \%$ of the 384 patients randomly assigned to the asparaginase arm. In both arms, median NSAA at each time-point increased progressively during the initial 6 weeks of treatment and then reached steady-state (not shown). Overall median steady-state NSAA was significantly higher on the FD arm. The percentage of NSAA determinations within the 0.10 to $0.14 \mathrm{IU} / \mathrm{mL}$ target range was similar for both arms, but there were fewer samples with high NSAA $(>0.14 \mathrm{IU} / \mathrm{mL})$ on the ID arm. The percentage of patients who tested positive for EC-Asnase antibodies was similar for the two arms $(P=.24)$.

Toxicity. There was no difference in the frequency of asparaginase-associated toxicity between the two arms (Table 4) or in the proportion of patients completing $\geq 25$ weeks of asparaginase (FD, 88\%; ID, 87\%).

Significantly more patients on the ID arm were switched from EC-Asnase to another asparaginase preparation (Table 4). The percentage of patients for whom the preparation was changed in response to clinical allergy was similar for the two arms (FD, 20\%; ID, 21\%). However, the preparation was switched for 19 ID patients $(10 \%)$ because of silent inactivation. Seventeen of these patients (90\%) had at least one NSAA $\geq 0.1 \mathrm{IU} / \mathrm{mL}$ after switching preparation. Conversely, $18 \mathrm{FD}$ patients $(9 \%)$ never had NSAA $\geq 0.1 \mathrm{IU} / \mathrm{mL}$ with EC-Asnase, never developed clinical allergies, and never changed preparations.

EFS and OS. Twenty-nine patients (15\%) on the FD arm experienced relapse compared with 17 ID patients (9\%). Five-year EFS was $82 \%$ (95\% CI, 75\% to 87\%) for FD and 90\% (95\% CI, 84\% to 94\%) for ID patients $(P=.04$; Fig 2C). The trend toward superior EFS with ID was observed in subsets defined by age, risk group, phenotype, and other characteristics (Table 3). There was no significant difference in 5 -year OS by arm (FD, 93\%; 95\% CI, 88\% to 96\%; ID, 96\%; 95\% CI, $92 \%$ to $98 \% ; P=.18)$.
For patients with at least one NSAA $\geq 0.1 \mathrm{IU} / \mathrm{mL}$ with ECAsnase, 5-year EFS was 85\% (95\% CI, 78\% to 90\%) for the FD arm compared with $90 \%$ for the ID arm (95\% CI, $83 \%$ to $95 \%$; $P=.16)$. For patients with persistently low NSAA with EC-Asnase (maximum NSAA $<0.1 \mathrm{IU} / \mathrm{mL}), 5$-year EFS was $73 \%(\mathrm{n}=36 ; 95 \% \mathrm{CI}, 52 \%$ to $86)$ on the FD arm and $91 \%$ on the ID arm ( $\mathrm{n}=51 ; 95 \%$ CI, $79 \%$ to $97 \% ; P=.058$ ). Five-year EFS for patients with persistently low EC-Asnase NSAA who never changed preparations was similar on both arms (FD: $\mathrm{n}=18 ; 76 \%$; $95 \% \mathrm{CI}, 38 \%$ to $92 \%$; ID: $\mathrm{n}=12 ; 78 \%$; $95 \% \mathrm{CI}, 35 \%$ to $94 \% ; P=.99)$. Five-year EFS for the 19 ID patients who switched to a different preparation for silent inactivation was 95\% (95\% CI, 68\% to $99 \%$ ).

We also explored the outcome of patients based on asparaginase antibody status. There was no significant difference in 5-year EFS in antibody-negative patients who never developed EC-Asnase clinical allergy (FD: $83 \%$; 95\% CI, $72 \%$ to $90 \%$; ID: $88 \%$; $95 \%$ CI, $78 \%$ to $92 \% ; P=.38$ ). For the 54 FD patients who developed antibodypositivity but never developed EC-Asnase clinical allergy, 5-year EFS was $84 \%$ (95\% CI, 70\% to $92 \%$ ) compared with $93 \%$ (95\% CI, $82 \%$ to $97 \%)$ for similar patients on the ID arm $(n=63 ; P=.12)$. Of note, zero $(0 \%)$ of 54 antibody-positive/EC-Asnase allergy-negative patients on the FD arm changed preparations, compared with 22 (35\%) of 63 of such patients on the ID arm, including all 19 patients who were switched for silent inactivation (Appendix).

\section{Randomization Interactions}

We investigated differences in CumInc of osteonecrosis and of fracture between the randomized asparaginase arms and found no statistically significant differences. No significant differences in asparaginase toxicities (clinical allergy, pancreatitis, or thrombosis) were found based on corticosteroid randomization. 


\begin{tabular}{|c|c|c|c|c|c|}
\hline \multirow[b]{2}{*}{ Characteristic } & \multicolumn{2}{|c|}{ Fixed Dose } & \multicolumn{2}{|c|}{ Individualized Dose } & \multirow[b]{2}{*}{$P$} \\
\hline & No. of Patients & $\%$ & No. of Patients & $\%$ & \\
\hline Patients randomly assigned & \multicolumn{2}{|l|}{195} & \multicolumn{2}{|l|}{189} & \\
\hline EC-Asnase dose, $1 \mathrm{IU} / \mathrm{m}^{2}$ & \multicolumn{2}{|c|}{25,000} & \multicolumn{2}{|c|}{$17,500^{*}$} & \\
\hline Any toxicity & 63 & 32 & 59 & 31 & .83 \\
\hline EC-Asnase clinical allergy & 39 & 20 & 40 & 21 & .80 \\
\hline Pancreatitis & 10 & 5 & 12 & 6 & .66 \\
\hline Thrombosis & 16 & 8 & 13 & 7 & .70 \\
\hline Completed $\geq 25$ week asparaginase & 172 & 88 & 164 & 86 & .76 \\
\hline Patients with evaluable NSAA data & 186 & 95 & 180 & 95 & \\
\hline No. of evaluable NSAA samples & \multicolumn{2}{|c|}{1,235} & \multicolumn{2}{|c|}{1,301} & \\
\hline Overall steady-state NSAA, IU/mL & & \multirow{2}{*}{\multicolumn{2}{|c|}{0.08}} & $<.001$ \\
\hline Median & & & & & \\
\hline Range & \multicolumn{2}{|c|}{$\begin{array}{c}0.11 \\
<0.025-1.78\end{array}$} & \multicolumn{2}{|c|}{$<0.025-0.74$} & \\
\hline \multicolumn{3}{|l|}{ Maximum NSAA in each patient } & & & .05 \\
\hline$\geq 0.10 \mathrm{IU} / \mathrm{mL}$ & 150 & 81 & 129 & 72 & \\
\hline$<0.10 \mathrm{IU} / \mathrm{mL}$ & 36 & 19 & 51 & 28 & \\
\hline EC-Asnase antibody determinations & 180 & & 181 & & .24 \\
\hline Positive test & 64 & 36 & 76 & 42 & \\
\hline Asparaginase preparation changed from EC-Asnase & 43 & 22 & 64 & 34 & .01 \\
\hline EC-Asnase clinical allergy & 39 & 20 & 39 & 21 & \\
\hline Silent inactivation & N/A & - & 19 & 10 & \\
\hline Other & 4 & 2 & 6 & 3 & \\
\hline Overall 5-year EFS, \% & & & & & .04 \\
\hline EFS & 8 & & 9 & & \\
\hline $95 \% \mathrm{Cl}$ & $75 t$ & & $84 \mathrm{tc}$ & & \\
\hline \multicolumn{6}{|l|}{ 5-year EFS of other subsets, \% } \\
\hline \multicolumn{6}{|l|}{ Maximum NSAA $\geq 0.10 \mathrm{IU} / \mathrm{mL}$} \\
\hline EFS & 8 & & 9 & & \\
\hline $95 \% \mathrm{Cl}$ & $78 t$ & & $83 \mathrm{tc}$ & & \\
\hline Maximum NSAA $<0.10 \mathrm{IU} / \mathrm{mL}$ & & & & & .16 \\
\hline EFS & 7 & & 9 & & \\
\hline $95 \% \mathrm{Cl}$ & $52 t$ & & 79 tc & & \\
\hline $\begin{array}{l}\text { Maximum NSAA }<0.10 \mathrm{IU} / \mathrm{mL} \text {, did not } \\
\text { change asparaginase preparation }\end{array}$ & & & & & .058 \\
\hline EFS & 7 & & 7 & & \\
\hline $95 \% \mathrm{Cl}$ & $38 t$ & & $35 \mathrm{tc}$ & & \\
\hline Changed asparaginase for silent inactivation & & & & & .99 \\
\hline EFS & $\mathrm{N}$ & & 9 & & \\
\hline $95 \% \mathrm{Cl}$ & & & $68 \mathrm{tc}$ & & \\
\hline
\end{tabular}

A total of 361 patients participated in both randomizations. When proportional hazard regression modeling was restricted to these patients, dexamethasone and ID EC-Asnase were both independent predictors of favorable EFS, without indication of an interaction (dexamethasone: hazard ratio, $0.49 ; P=.02$; ID: hazard ratio, $0.52 ; P=.04)$.

\section{DISCUSSION}

Our study demonstrates that postinduction dexamethasone and ID of L-asparaginase improve EFS in pediatric patients with newly diagnosed ALL.

A novel aspect of our trial was the investigation of ID of ECAsnase. ${ }^{23}$ We demonstrate the feasibility of adjusting the dose of EC-Asnase based on measurement of NSAA in the context of a large multi-institutional study. ID was associated with superior EFS, but did not decrease asparaginase-associated toxicity, increase the proportion of patients able to complete the planned treatment course of asparaginase, or lead to higher (potentially more therapeutic) steady-state NSAA with EC-Asnase.

One possible explanation for this result was that silent inactivation was prospectively identified on the ID but not the FD arm. ID patients with silent inactivation switched asparaginase preparations, but on the FD arm preparation was changed only for clinical allergy. FD patients with low EC-Asnase NSAA (maximum $<0.1 \mathrm{IU} / \mathrm{mL}$ ) who never switched preparations had a 5 -year EFS of $76 \%$ compared with $95 \%$ for the ID patients who switched preparations for silent inactivation. We and others have previously demonstrated that patients with EC-Asnase hypersensitivity and antibody-positivity achieved therapeutic NSAA after switching preparations. ${ }^{16,24}$ 
Furthermore, we demonstrate that patients with silent inactivation also achieve therapeutic NSAA with change in preparation (17 of 19 ID patients with silent inactivation had at least one therapeutic NSAA after switching preparations). Our results suggest that prospectively monitoring for the development of silent inactivation (and not just clinical allergy) and changing asparaginase preparation may improve outcome. In our trial that is currently enrolling, we are monitoring NSAA in real time and switching asparaginase preparation in patients with presumed silent inactivation (two consecutive nondetectable NSAA measurements).

Our results also support the use of dexamethasone instead of prednisone during postinduction treatment phases. There is controversy regarding whether dexamethasone is superior to prednisone. Two trials showed dexamethasone superiority ${ }^{3,4}$ whereas others demonstrated no differences in outcome by corticosteroid type. ${ }^{5,6} \mathrm{We}$ demonstrate that dexamethasone was associated with better EFS in all examined patient subsets.

The beneficial impact of dexamethasone in reducing relapse risk comes at a cost of increased toxicity, primarily in older children and adolescents. Osteonecrosis can lead to severe pain, joint damage, and articular collapse and can necessitate invasive procedures. ${ }^{7,25-31}$ Dexamethasone was associated with an increased risk of osteonecrosis and fracture only in patients ages 10 to 18 years. Neither corticosteroid type nor cumulative dose of corticosteroid affected the rate of osteonecrosis in younger patients (ages 1 to 9.99 years). We and others have reported that dexamethasone was associated with higher rates of infection and death when given during induction in conjunction with an anthracycline. ${ }^{32,33}$ In this article, we demonstrate that dexamethasone was associated with a higher risk of infection during postinduction treatment, particularly in older children and adolescents, but that risk did not result in a higher toxic death rate.

A limitation of this study is that detailed subgroup analyses of EFS and OS were limited by sample size. In addition, analyses of outcome based on NSAA and asparaginase antibody status were exploratory.

In summary, there was no overall difference in skeletal toxicity by corticosteroid type. Dexamethasone was associated with a higher infection rate and, in older children, increased incidence of osteonecrosis and fracture. In addition, we found no difference in asparaginaserelated toxicity by EC-Asnase dosing method. Dexamethasone and pharmacokinetically guided individualized dosing of asparaginase were each associated with favorable EFS. Importantly, dexamethasone was associated with a better outcome in younger patients ( 1 to 10 years old) without any increased risk in skeletal toxicity. Considering its beneficial impact in reducing relapse risk, we continue to use dexamethasone in postinduction therapy for all age groups. Future studies should focus on minimizing the toxicity of dexamethasone in older pediatric patients without compromising efficacy. Our results suggest that pharmacokinetic monitoring during treatment with EC-Asnase to identify patients with silent inactivation may be an effective strategy to improve the outcome of children and adolescents with ALL.

\section{AUTHORS' DISCLOSURES OF POTENTIAL CONFLICTS OF INTEREST}

Although all authors completed the disclosure declaration, the following author(s) and/or an author's immediate family member(s) indicated a financial or other interest that is relevant to the subject matter under consideration in this article. Certain relationships marked with a " $U$ " are those for which no compensation was received; those relationships marked with a "C" were compensated. For a detailed description of the disclosure categories, or for more information about ASCO's conflict of interest policy, please refer to the Author Disclosure Declaration and the Disclosures of Potential Conflicts of Interest section in Information for Contributors. Employment or Leadership Position: None Consultant or Advisory Role: Lewis B. Silverman, Enzon Pharmaceuticals (C), EUSA Pharma (C) Stock Ownership: None Honoraria: None Research Funding: Jeffrey G. Supko, EUSA Pharma; Mary V. Relling, Sigma-Tau Pharmaceuticals, Enzon Pharmaceuticals; Stephen E. Sallan, Enzon Pharmaceuticals, EUSA Pharma Expert Testimony: None Other Remuneration: None

\section{AUTHOR CONTRIBUTIONS}

Conception and design: Jeffrey G. Supko, Barbara L. Asselin, Uma H. Athale, Luis A. Clavell, Marshall Schorin, Harvey J. Cohen, Stephen E. Sallan, Lewis B. Silverman

Provision of study materials or patients: Barbara L. Asselin, Uma H. Athale, Luis A. Clavell, Kara M. Kelly, Marshall Schorin, Lewis B. Silverman

Collection and assembly of data: Lynda M. Vrooman, Jeffrey G. Supko, Jane O’Brien, Uma H. Athale, Kara M. Kelly, Jeffery L. Kutok, Bruno Michon, Mary V. Relling, Stephen E. Sallan, Lewis B. Silverman Data analysis and interpretation: Lynda M. Vrooman, Kristen E. Stevenson, Jeffrey G. Supko, Suzanne E. Dahlberg, Uma H. Athale, Kara M. Kelly, Jeffery L. Kutok, Caroline Laverdière, Steven E. Lipshultz, Marshall Schorin, Harvey J. Cohen, Donna S. Neuberg, Stephen E. Sallan, Lewis B. Silverman

Manuscript writing: All authors

Final approval of manuscript: All authors

\section{REFERENCES}

1. Jones B, Freeman Al, Shuster JJ, et al: Lower incidence of meningeal leukemia when prednisone is replaced by dexamethasone in the treatment of acute lymphocytic leukemia. Med Pediatr Oncol 19:269-275, 1991

2. Gaynon PS, Lustig RH: The use of glucocorticoids in acute lymphoblastic leukemia of childhood: Molecular, cellular, and clinical considerations. J Pediatr Hematol Oncol 17:1-12, 1995

3. Bostrom BC, Sensel MR, Sather HN, et al: Dexamethasone versus prednisone and daily oral versus weekly intravenous mercaptopurine for patients with standard-risk acute lymphoblastic leukemia: A report from the Children's Cancer Group. Blood 101:3809-3817, 2003
4. Mitchell CD, Richards SM, Kinsey SE, et al: Benefit of dexamethasone compared with prednisolone for childhood acute lymphoblastic leukaemia: Results of the UK Medical Research Council ALL97 randomized trial. Br J Haematol 129:734-745, 2005

5. Igarashi $S$, Manabe $A$, Ohara $A$, et al: No advantage of dexamethasone over prednisolone for the outcome of standard- and intermediate-risk childhood acute lymphoblastic leukemia in the Tokyo Children's Cancer Study Group L95-14 protocol. J Clin Oncol 23:6489-6498, 2005

6. De Moerloose B, Suciu S, Bertrand Y, et al: Improved outcome with pulses of vincristine and corticosteroids in continuation therapy of children with average risk acute lymphoblastic leukemia (ALL) and lymphoblastic non-Hodgkin lymphoma (NHL): Report of the EORTC randomized phase 3 trial 58951. Blood 116:36-44, 2010
7. Strauss AJ, Su JT, Dalton VM, et al: Bony morbidity in children treated for acute lymphoblastic leukemia. J Clin Oncol 19:3066-3072, 2001

8. Silverman LB, Gelber RD, Dalton VK, et al: Improved outcome for children with acute lymphoblastic leukemia: Results of Dana-Farber Consortium Protocol 91-01. Blood 97:1211-1218, 2001

9. Ahlke E, Nowak-Göttl U, Schulze-Westhoff P, et al: Dose reduction of asparaginase under pharmacokinetic and pharmacodynamic control during induction therapy in children with acute lymphoblastic leukaemia. Br J Haematol 96:675-681, 1997

10. Avramis VI, Sencer S, Periclou AP, et al: A randomized comparison of native Escherichia coli asparaginase and polyethylene glycol conjugated asparaginase for treatment of children with newly diagnosed standardrisk acute lymphoblastic leukemia: A Children's Cancer Group study. Blood 99:1986-1994, 2002 
11. Berg SL, Balis FM, McCully $C L$, et al: Pharmacokinetics of PEG-L-asparaginase and plasma and cerebrospinal fluid L-asparagine concentrations in the rhesus monkey. Cancer Chemother Pharmacol 32:310-314, 1993

12. Boos J, Werber G, Ahlke E, et al: Monitoring of asparaginase activity and asparagine levels in children on different asparaginase preparations. Eur J Cancer 32A:1544-1550, 1996

13. Riccardi $R$, Holcenberg JS, Glaubiger DL, et al: L-asparaginase pharmacokinetics and asparagine levels in cerebrospinal fluid of rhesus monkeys and humans. Cancer Res 41:4554-4558, 1981

14. Rizzari C, Zucchetti M, Conter V, et al: $\mathrm{L}$-asparagine depletion and L-asparaginase activity in children with acute lymphoblastic leukemia receiving i.m. or i.v. Erwinia C or E coli L-asparaginase as first exposure. Ann Oncol 11:189-193, 2000

15. Avramis VI, Panosyan EH: Pharmacokinetic/ pharmacodynamic relationships of asparaginase formulations: The past, the present and recommendations for the future. Clin Pharmacokinet 44:367-393, 2005

16. Vrooman LM, Supko JG, Neuberg DS, et al: Erwinia asparaginase after allergy to E. coli asparaginase in children with acute lymphoblastic leukemia. Pediatr Blood Cancer 54:199-205, 2010

17. Silverman LB, McLean TW, Gelber RD, et al: Intensified therapy for infants with acute lymphoblastic leukemia: Results from the Dana-Farber Cancer Institute Consortium. Cancer 80:2285-2295, 1997
18. Silverman $L B$, Gelber $R D$, Young $M L$, et al: Induction failure in acute lymphoblastic leukemia of childhood. Cancer 85:1395-1404, 1999

19. Moghrabi A, Levy DE, Asselin B, et al: Results of the Dana-Farber Cancer Institute ALL Consortium Protocol 95-01 for children with acute lymphoblastic leukemia. Blood 109:896-904, 2007

20. Kawedia JD, Liu C, Pei D, et al: Dexamethasone exposure and asparaginase antibodies affect relapse risk in acute lymphoblastic leukemia. Blood 119:1658-1664, 2012

21. Liu C, Kawedia JD, Cheng C, et al: Clinical utility and implications of asparaginase antibodies in acute lymphoblastic leukemia. Leukemia 26:2303-2309, 2012

22. Zhou J, Goldwasser MA, Li A, et al: Quantitative analysis of minimal residual disease predicts relapse in children with $\mathrm{B}$-lineage acute lymphoblastic leukemia in DFCl ALL Consortium Protocol 9501. Blood 110:1607-1611, 2007

23. Evans WE, Relling MV, Rodman $\mathrm{JH}$, et al: Conventional compared with individualized chemotherapy for childhood acute lymphoblastic leukemia. N Engl J Med 338:499-505, 1998

24. Willer A, Gerss J, König T, et al: AntiEscherichia coli asparaginase antibody levels determine the activity of second-line treatment with pegylated $\mathrm{E}$ coli asparaginase: A retrospective analysis within the ALL-BFM trials. Blood 118:57745782, 2011

25. Mattano LA Jr, Sather HN, Trigg ME, et al: Osteonecrosis as a complication of treating acute lymphoblastic leukemia in children: A report from the Children's Cancer Group. J Clin Oncol 18:32623272, 2000

26. Werner $A$, Jäger $M$, Schmitz $H$, et al: Joint preserving surgery for osteonecrosis and osteochondral defects after chemotherapy in childhood. Klin Padiatr 215:332-337, 2003

27. Davies JH, Evans BA, Jenney $M E$, et al: Skeletal morbidity in childhood acute lymphoblastic leukaemia. Clin Endocrinol (Oxf) 63:1-9, 2005

28. Bürger $B$, Beier R, Zimmermann $M$, et al: Osteonecrosis: A treatment related toxicity in childhood acute lymphoblastic leukemia (ALL) -Experiences from trial ALL-BFM 95. Pediatr Blood Cancer 44:220-225, 2005

29. Patel B, Richards SM, Rowe JM, et al: High incidence of avascular necrosis in adolescents with acute lymphoblastic leukaemia: A UKALL XII analysis. Leukemia 22:308-312, 2008

30. Pui $\mathrm{CH}$, Campana $\mathrm{D}$, Pei $\mathrm{D}$, et al: Treating childhood acute lymphoblastic leukemia without cranial irradiation. N Engl J Med 360:2730-2741, 2009

31. Kawedia JD, Kaste SC, Pei D, et al: Pharmacokinetic, pharmacodynamic, and pharmacogenetic determinants of osteonecrosis in children with acute lymphoblastic leukemia. Blood 117:2340-2347, 2011

32. Hurwitz CA, Silverman LB, Schorin MA, et al: Substituting dexamethasone for prednisone complicates remission induction in children with acute lymphoblastic leukemia. Cancer 88:1964-1969, 2000

33. Belgaumi AF, Al-Bakrah M, Al-Mahr M, et al: Dexamethasone-associated toxicity during induction chemotherapy for childhood acute lymphoblastic leukemia is augmented by concurrent use of daunomycin. Cancer 97:2898-2903, 2003

\section{Support}

Supported in part by Grants No. 5 P01CA068484 and P30 21765 from the National Cancer Institute, by the American Lebanese Syrian Associated Charities, and by the Linde Family Foundation. 